\title{
Potential Therapeutic Effect of Allogenic Mesenchymal Stem Cells on Chronic Cerebral Murine Toxoplasmosis
}

\author{
Ayman Mohamed El-Ashkar ${ }^{1,2}$,Laila Mohammed El-Hosseiny ${ }^{1}$,Fatma \\ Abdelkarim Abu Zahra ${ }^{3}$, Nermeen Mohammed Abd El-Samee ${ }^{1}$, Ashraf \\ Mohammed Barakat ${ }^{4}$, Shimaa Abdelraouf Elgohary ${ }^{5}$, Abeer Fathy Badawy ${ }^{1}$ \\ ${ }^{1}$ Department of Medical Parasitology, Faculty of Medicine, Ain Shams University, Egypt. \\ ${ }^{2}$ Department of Basic Medical Science, College of Medicine, University of Bisha, KSA. \\ ${ }^{3}$ Medical Research Centre, Faculty of Medicine - Ain Shams University, Egypt. \\ ${ }^{4}$ Department of Zoonotic Diseases, National research centre, Dokki, Giza, Egypt. \\ ${ }^{5}$ Department of Pathology, Faculty of Medicine, Ain Shams University, Egypt.
}

Corresponding Author Ayman Mohamed ElAshkar

Mobile:

$+201030876995 /$

$+966502341013$

E mail: aymanpara@yahoo.co $m$

Key words: Mesenchymal Stem Cells; $\quad$ Murine toxoplasmosis; SpiramycinMetronidazole
Background and Aim: Toxoplasma infection is mainly latent and cause severe disease only if reactivation occurs especially for brain cysts. This study aimed to evaluate the therapeutic effect of BM-MSCs on murine chronic toxoplasmosis experimental model.

Methods: Female Swiss albino mice $(n=100)$ were divided into 5 groups (20 mice each). Group I (infected, injected with BM-MSCs); Group II (infected, treated with BM-MSCs and SpiramycinMetronidazole); Group III (infected, treated with Spiramycin-Metronidazole); Group IV (infection control) and Group V (non infected, injected with BM-MSCs).

Results: In Regarding the mean Toxoplasma brain cyst count, after 7 and 14 days, group I was significantly lower than group II, higher than group III and non-statistically different from group IV. Group II was significantly higher than in groups III and IV. Group III showed a significant decrease in brain cyst count versus group IV. As regards the histopathological examination of brain sections, after 7 and 14 days, group I showed the least histopathological inflammatory changes which was significantly lower than that of group IV. Group II revealed the most profound histopathological inflammatory changes. Group III showed mild to moderate inflammatory changes with a nonsignificant difference from group IV. As regards the survival rate, the group I showed the highest, group II showed the lowest mean survival time, which was statistically significant versus group IV. Group III showed a non-significant difference versus group IV.

Conclusion: MSCs have an antiinflammatory effect and prolong the survival of $T$. gondii infected mice; however, they have a non-significant effect on brain cyst count.

\section{INTRODUCTION}

Toxoplasmosis is an infectious disease which affects around > 60\% of some populations worldwide [1]. The most common form of infection in humans is latent but in immunosuppressed patients, it may cause serious disease mainly through reactivation of cerebral toxoplasmosis which has severe neurological outcomes that may cause death [2]. Recent findings indicated that latent toxoplasmosis may play various roles in the etiology of different mental disorders such as schizophrenia, Alzheimer's and Parkinson's diseases [3].
The outcome of an infection with toxoplasmosis depends on a balance between pro-inflammatory (IL-12, IFN- $\gamma$ and TNF- $\alpha$ ) and antiinflammatory (IL-10, IL-27,TGF-1 $\beta$ )) signals that inhibit parasite proliferation and also control the inflammatory response. Absence of any one of these pro-inflammatory mediators leads to higher mortality during infection due to uncontrolled tachyzoite growth [4]. The brains of infected mice showed evidence of inflammatory infiltration, gliosis together with $T$. gondii cysts and proinflammatory cytokines [5]. 
The treatment of toxoplasmosis involves a combination of pyrimethamine and sulfadiazine, but their efficacy is limited due to significant toxicity or development of drug-resistances in parasites. Unfortunately, the available therapies affect only tachyzoites in acute infection but can't affect tissue cystic stage in chronic infection [6]. Spiramycin, when co-administered with metronidazole showed significant effect on the treatment of chronic toxoplasmosis [7].

Mesenchymal stem cells (MSCs) are selfrenewing, clonal precursors of nonhaematopoietic tissues, have the capacity to differentiate to the major specialized cell types [8]. The transplantation of MSCs has emerged as a promising tool for the repair of several tissues, including the CNS [9]. Stem cells can cross the blood brain barrier (BBB) and reverse neuronal damage [10]. MSC treatment modulates the immune response and decrease the expression of pro-inflammatory cytokines, directing the immune response from a predominantly proinflammatory to an anti-inflammatory profile $[11,12]$. MSCs secret certain cytokines that are helpful for anti-apoptosis and antifibrosis, including vascular endothelial, insulin-like, and hepatocyte growth factors [13]. Recently, stem cell therapy was evaluated in the treatment of parasitic infections. MSCs were found to relieve liver injury and fibrosis caused by $S$. japonicum and prolongs the survival of infected mice [14]. There was a trial to use MSCs in Leishmania major infection and cerebral malaria [15] [16].

The aim of this study is to evaluate the potential therapeutic effect of allogenic mesenchymal stem cells on chronic cerebral toxoplasmosis in experimentally infected mice.

\section{MATERIAL AND METHOD \\ Isolation and Culture of BM-MSCs}

Sterile phosphate-buffered saline (PBS) was thoroughly used to wash bone marrow that was obtained aseptically from tibiae and femurs of 7wk-old male Albino donor rats. The cavities of the bone marrow were flushed into $15 \mathrm{ml}$ sterile falcon tubes, by complete medium containing; $100 \mathrm{ml}$ Dulbecco's Modified Eagle's Medium (DMEM), $12 \mathrm{ml}$ fetal bovine serum, $1 \mathrm{ml}$ penicillin/streptomycin mixture (5000 units $/ \mathrm{mL}$ of penicillin and $5000 \mu \mathrm{g} / \mathrm{mL}$ of streptomycin) and $50 \mu \mathrm{l}$ of $250 \mu \mathrm{g} / \mathrm{ml}$ Amphotericin B (Lonza, Switzerland). We harvested and re-suspended the nucleated cells in the complete medium inside sterile flask $25 \mathrm{~cm}^{2}$ (NUNC Company, Denmark). Cells were incubated at $37{ }^{\circ} \mathrm{C}$ in $5 \%$ humidified $\mathrm{CO} 2$ with daily examination by Axiovert -inverted microscope- 100ZEISS. When cultures become confluent, the cultures were treated with $2 \mathrm{ml}$ of $0.25 \%$ trypsin $/ 0.02 \%$ EDTA for $2 \mathrm{~min}$ at $37{ }^{\circ} \mathrm{C}$ to detach cells from the flasks. Trypan blue was used to test the viability of cells, and then a hemocytometer was used to count the cells and adjusted to $10^{6}$ cells $/ \mathrm{ml}$, then used immediately for animal treatment [17].

\section{Characterization of the cultured BM-MSCs}

\section{A. Fixation and Staining of BM-MSCs [18]:}

a. A sterile pipette was used to obtain the medium, and then sterile PBS was used to wash the adherent cells twice.

b. On day 9 of culture, fixation step was performed for the adherent MSCs by using freshly prepared pre-cooled mixture of acetone/methanol that was added to the culture dish with incubation at room temperature for 10 minutes.

c. Giemsa stain was applied to the fixed adherent MSCs.

d. The culture dishes were incubated with the staining solution for 30 minutes and then washed with running $\mathrm{H}_{2} \mathrm{O}$. By using the inverted microscopy, we examined the dishes then took photographs. The cells appeared as fibroblast-like shaped cells (fig.1).

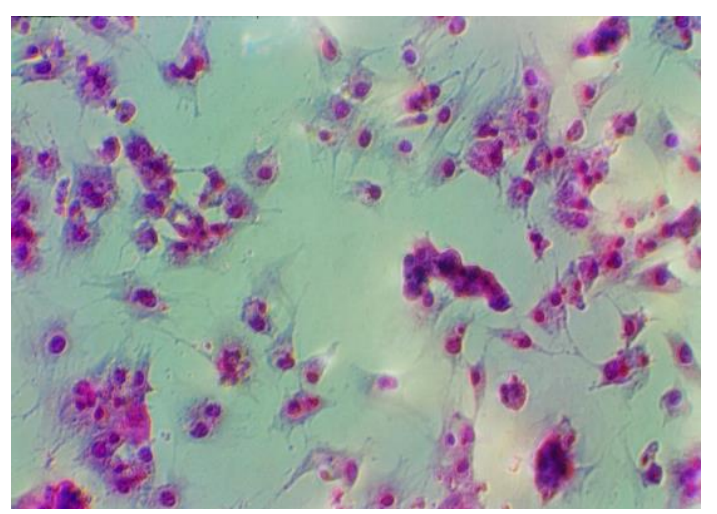

Fig. (1): Showing Giemsa stained BM-MSCs with bluish cytoplasm and vesicular nucleus (Axiovert -inverted microscope X200)

\section{B. Immunocytochemical characterization [19].}

The cultured BM-MSCs were characterized by using the streptavidin-biotin immune-peroxidase 
technique for CD44 and CD 34 in the cultured cells.

a. The Petri dish was fixed on day 12 of culture by Acetone: Methanol (1:1).

b. The fixative was removed, and then the PBS was used to wash the cells twice.

c. The dish was covered by $\mathrm{H}_{2} \mathrm{O}_{2}(10 \%)$ for 15 minutes to block endogenous peroxidase.

d. Then the 1ry antibody was added. Antibodies were diluted in PBS.

e. The Petri-dish was incubated with the primary antibody for 1 hour at $37^{\circ} \mathrm{C}$. The Petri-dish was washed three times with PBS.

f. The Petri-dish was incubated with the secondary antibody diluted in PBS for another 1 hour at $37^{\circ} \mathrm{c}$.

g. The Petri-dish was washed 3 times with PBS.

h. The Petri-dish was covered completely by 80 $100 \mathrm{ml}$ of Streptavidin horseradish peroxidase conjugate for 15 minutes, then washing twice with PBS.

i. The color was developed using 1-2 $\mathrm{ml}$ of Diaminobenzidine for 10 minutes. Then, Petri-dishes were washed well with distilled water.

j. Positive nuclear reactions appeared brown in color (fig.2).

Negative control was performed using the $2^{\text {nd }}$ antibody only to check for any cross reaction (fig.3).

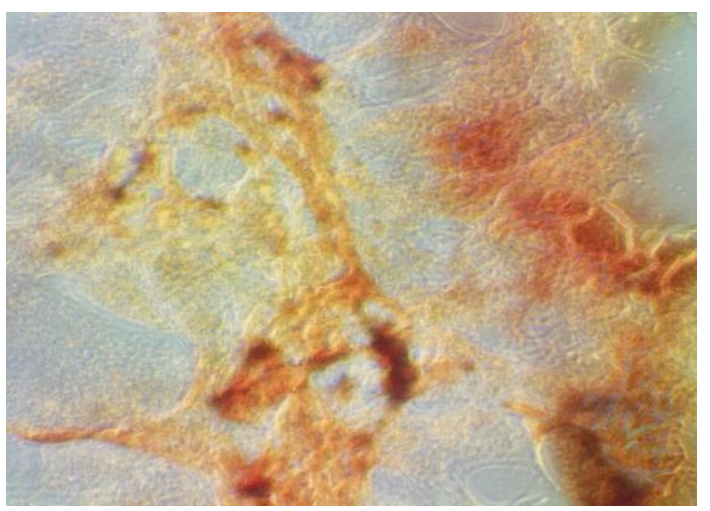

Fig. (2): Immuno-stained BM-MSCs with positive brownish immune reaction for anti-CD 44 antibody (Axiovert -inverted microscope X200).

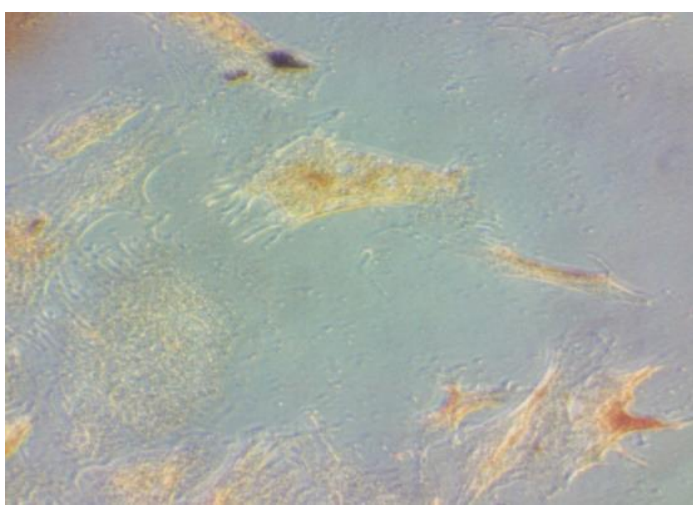

Fig. (3): Immuno-stained BM-MSCs with negative immune reaction for anti-CD 34 antibody (Axiovert -inverted microscope X200).

\section{Parasite}

Me49 non-virulent strain of $T$. gondii was kindly provided by Zoonotic Diseases Department, Division of Veterinary Research, National Research Centre, Giza, Egypt. The parasite strain was regularly maintained by repeated oral inoculation of Swiss albino mice with 20 brain cysts $/ 0.2 \mathrm{ml} /$ mouse of brain homogenate of previously infected mice every $2-3$ months to establish chronic toxoplasmosis [20].

\section{Experimental animal grouping and study design.}

Female Swiss Albino mice ( $\mathrm{n}=100), 7$ weeks old and weighing about 25-30 gm were maintained under conventional conditions (fed a standard commercial diet, housed in 12-hour dark cycle at $22 \pm 2{ }^{\circ} \mathrm{C}$ and continuous air renovation) at Medical Research Center, Faculty of Medicine, Ain Shams University.

Mice ( $\mathrm{n}=80$ ) were infected orally, using a nasogastric feeding tube, by brain homogenate of the Me49 strain of $T$. gondii with a dose of 20 cysts $/ 0.2 \mathrm{ml} /$ mouse [21]. Infection was guaranteed by finding $T$. gondii brain cysts 2 months post-infection in Giemsa stained brain homogenate. Chronic toxoplasmosis infected mice were divided into 4 groups of 20 mice each, as follows:

Group I (infected-MSCs treated) $(\mathrm{n}=20)$ : Chronically infected mice, intravenously injected in the tail vein with a single dose of $5 \times 10^{5}$ allogenic MSCs $/ 0.5 \mathrm{ml} /$ mouse [17], 2 months post-infection.

Group II (infected-MSCs and drug treated) $(n=20)$ : Chronically infected mice, treated with both; a single dose of $5 \times 10^{5}$ allogenic MSCs $/ 0.5 \mathrm{ml} /$ mouse, IV injection in the tail vein 
and Spiramycin (400 mg/kg)- Metronidazole $(500 \mathrm{mg} / \mathrm{kg})$, orally as liquid suspensions, using a nasogastric feeding tube, daily for 7 days, 2 months post-infection.

Group III (infected-drug treated) $(\mathrm{n}=20)$ : Chronically infected mice, treated with 400 $\mathrm{mg} / \mathrm{kg}$ of Spiramycin (Medical Union Pharmaceuticals) and $500 \mathrm{mg} / \mathrm{kg}$ of Metronidazole (Sanofi Aventis). The drugs were orally administered as liquid suspensions, using a nasogastric feeding tube, daily for 7 days; 2 months post-infection [7].

Group IV (infection control group) $(\mathrm{n}=20)$ : Chronically infected mice with a dose of 20 cysts $/ 0.2 \mathrm{ml} /$ mouse orally, using a nasogastric feeding tube.

Group V (MSCs-control group) $(\mathrm{n}=20)$ : Noninfected mice, IV injection in the tail vein with a single dose of $5 \times 10^{5}$ allogenic MSCs/0.5ml/mouse [17].

Mice ( $n=5)$ from each group were euthanized by cervical dislocation, at the $7^{\text {th }}, 14^{\text {th }}$ days after starting treatment administration (SpiramycinMetronidazole and MSCs), according to the previously mentioned animal grouping [22, 7] (Fig 4).

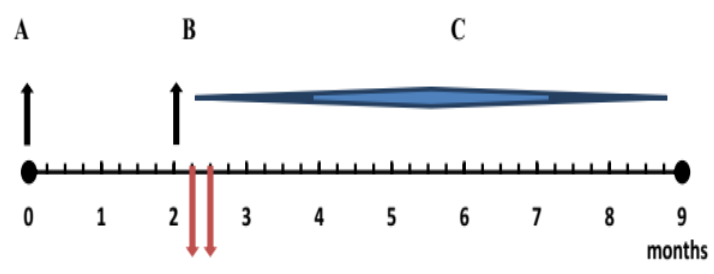

DE

Fig. (4): A scaled line into 9 months showed the study period, A: The start of mice infection with Me49 non-virulent strain of $T$. gondii. B: Infection was established in mice 2 months after infection, also treatment administration (Spiramycin-Metronidazole and or MSCs) was started, according to the previously mentioned animal grouping. C: Deaths of mice (10 mice in each group) were recorded daily for 7 months, 2 months post-infection. D: 5 mice from every group were euthanized 7 days after starting treatment administration. E: 5 mice from every group were euthanized 14 days after starting treatment administration.

\section{PCR detection of male-derived MSCs}

Genomic DNA was extracted from the mice brain tissue homogenate in each test group, using Wizardt Genomic DNA purification kit
(Promega, Madison, Wisconsin). The presence or absence of the sex determination region on male $\mathrm{Y}$ chromosome (sry) gene in recipient female mice was assessed by PCR to amplify a product of 104 vase pairs (bp). Separation of PCR products were done by $2 \%$ agarose gel electrophoresis and stained with ethidium bromide. Positive and negative controls were included in each assay [23].

\section{Evaluation of MSCs and drug treatment:}

\section{1- Brain cyst count}

Mice $(n=5)$ from each group were euthanized by cervical dislocation, on the $7^{\text {th }}, 14^{\text {th }}$ days after starting treatment administration. Each brain sample was rinsed with sterile saline solution, followed by homogenization. Then, glass slide was made by putting $25 \mathrm{ul}$ of brain homogenate on it (4 slides for each brain sample), allowed to dry in the air, then fixed and stained with methanol and Giemsa stain respectively. Using a compound microscope, the number of cysts were counted and calculated in each brain [7].

\section{2- Histopathological examination}

Paraffin blocks were made after fixation of brain samples in $10 \%$ formalin. The thickness of the sections was $4-\mu \mathrm{m}$. The sections were then rehydrated and stained with hematoxylin and eosin (H\&E). All the slides were examined by pathologist who was blinded to the experimental design. scoring of brain inflammation (0-4) was determined as follows; score 0: no lesion, score 1: minimal lesion restricted to localized perivascular cuffs with slight meningeal mononuclear cell infiltration score 2: mild lesion involving perivascular cuffs, local glial cell infiltration, and meningitis score 3: moderate lesion involving perivascular cuffs, glial cell activation, meningitis, focal necrosis, and rarefaction of the neuropil with occasional macrophage infiltration score 4: severe lesion involving perivascular cuffs, glial cell activation, meningitis, rarefaction of the neuropil, and focally extensive necrosis [24].

Image analysis for brain cyst diameter was performed by two pathologists independently, using computerized Image Analyzing Software (Special SIS starter. version 3.2, Olympus, Germany) which is connected to an Olympus microscope (model BX51, Olympus, Japan). 


\section{3- Mice survival}

Mice $(n=10)$ from each group were monitored daily and deaths were recorded for 7 months, 2 months post infection.

\section{Statistical analysis}

SPSS software package version 17.0 was used for data analysis. Quantitative data was expressed using mean and standard deviation. Differences were considered significant if $\mathrm{P}$ values were equal to or less than 0.05 by Student " $t$ " test.

One way ANOVA test, after 7 and 14 days post treatment was performed.

Survival of mice on different drug regimens was evaluated by the Kaplan-Meier product limit method, also the difference between the curves obtained was analyzed by Log Rank test.

\section{RESULTS}

\section{1- Brain cyst count}

Counting of brain cyst 7 days after treatment revealed that, group I (3784 \pm 534$)$ was nonstatistically $(\mathrm{p}>0.05)$ different from group IV $(2878 \pm 277)$. Group II $(5559 \pm 656)$ was significantly ( $<<0.05)$ higher than group I (3784 $\pm 534)$ and group IV $(2878 \pm 277)$. Group III, showed the lowest mean cysts count $(1527 \pm$ $119)$ which was considerably ( $p<0.05)$ less than that of group IV (2878 \pm 277$)$ Fig. (5).

Counting of brain cyst 14 days after treatment revealed that, group I $(3533 \pm 727)$ was nonstatistically $(\mathrm{p}>0.05)$ different from group IV $(2908 \pm 260)$. Group II $(5569 \pm 667)$ was significantly ( $<<0.05)$ higher than group I (3533 $\pm 727)$ and group IV $(2908 \pm 260)$. Group III showed the lowest mean cysts count $(1479 \pm$ 94.1) which was considerably $(\mathrm{p}<0.05)$ less than that of group IV $(2908 \pm 260)$ Fig. (6).

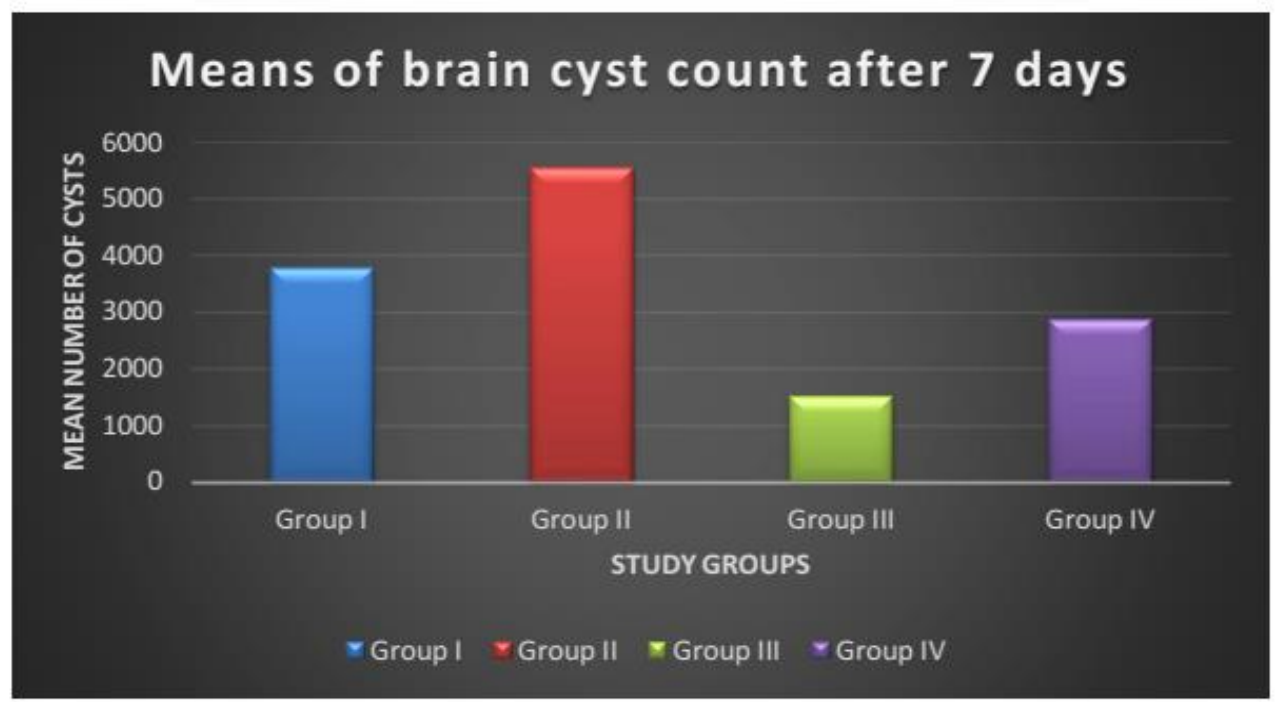

Bar chart illustrating mean count of brain cysts, in all infected groups 7 days after the start of treatment administration.

Fig (5): Mean count of brain cysts in all infected groups, 7 days after the start of treatment administration. 


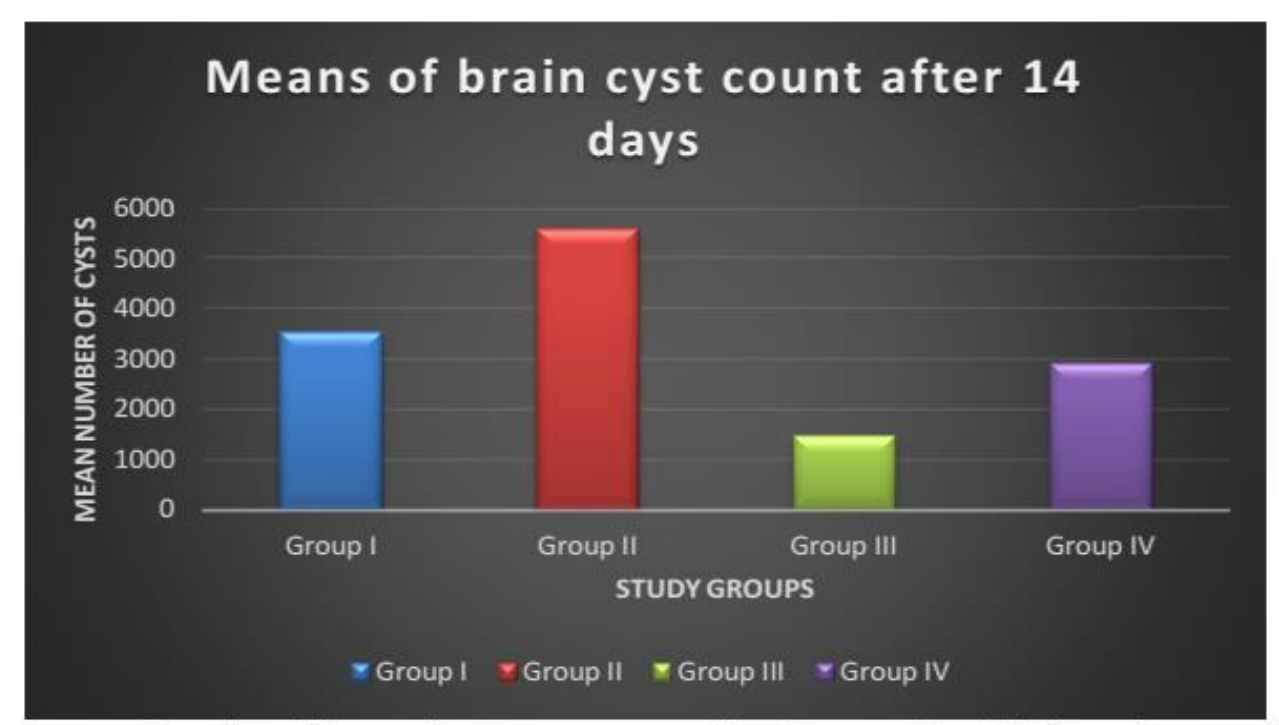

Bar chart illustrating mean count of brain cysts, in all infected groups 14 days after the start of treatment administration.

Fig. (6): Mean count of brain cysts in all infected groups, 14 days after the start of treatment administration

\section{2- Histopathological examination}

Histopathological examination of brain sections revealed tissue cysts in all infected groups (Fig. 7). Scoring of brain inflammation (1-3) was determined [25]. Group I showed mild histopathological changes (score 1). The cerebral architecture was slightly preserved with apparently less dark nuclei with multiple normal pyramidal cells and less inflammatory reaction (Fig. 8). Group II revealed profound histopathological changes (score 3). Multiple deformed neurons with dark shrunken nuclei together with acidophilic masses of inflammatory cells were detected. Foci showed gliosis, numerous lymphoid cells and macrophages infiltration of perivascular and leptomeningeal areas (Fig. 9). Group III showed minimal to moderate inflammatory changes (score from 1 to 2). Few neurons were deformed and shrunken with acidophilic cytoplasm and dark nuclei. Focal mononuclear inflammatory infiltrate and focal necrosis were noticed (Fig. 10). Group IV showed moderate inflammatory changes (score 2). Perivascular cuffing by lymphocytes, focal mononucleated cell infiltrates and focal areas of gliosis were noticed (Fig. 11). Group V showed normal cerebral architecture (Fig. 12).

Histopathological examination showed the same picture at the $7^{\text {th }}$ and the $14^{\text {th }}$ day after starting treatment administration.

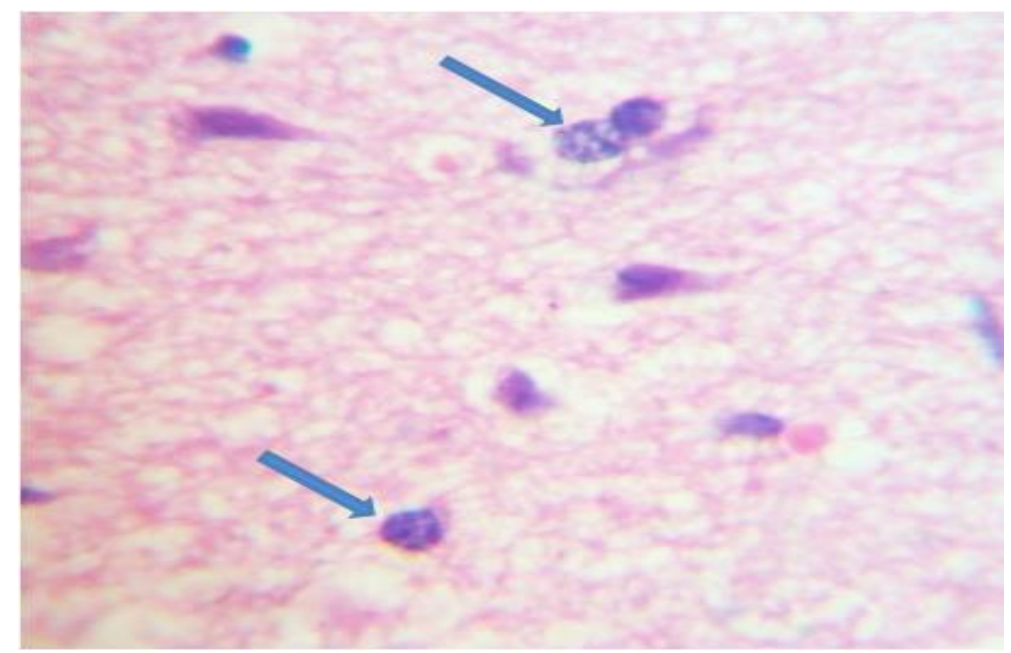

Fig. (7): Brain section of group IV showing T. gondii cysts containing bradyzoites "blue arrow" (H\&E stain $\times 1000)$.

El-Hosseiny et al., Afro-Egypt J Infect Endem Dis 2020;10(2):129-140

https://aeji.journals.ekb.eg/

http://mis.zu.edu.eg/ajied/home.aspx 


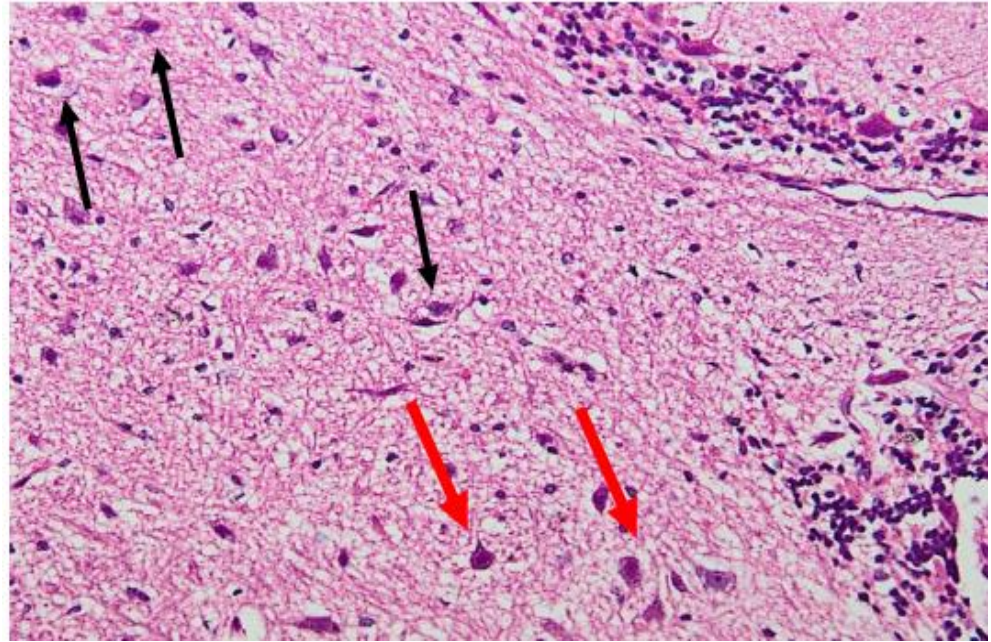

Fig. (8): Brain section of group I showing slightly preserved with apparently less dark nuclei "black arrow" with multiple normal pyramidal cells "red arrow" (H\&E stain x 400)

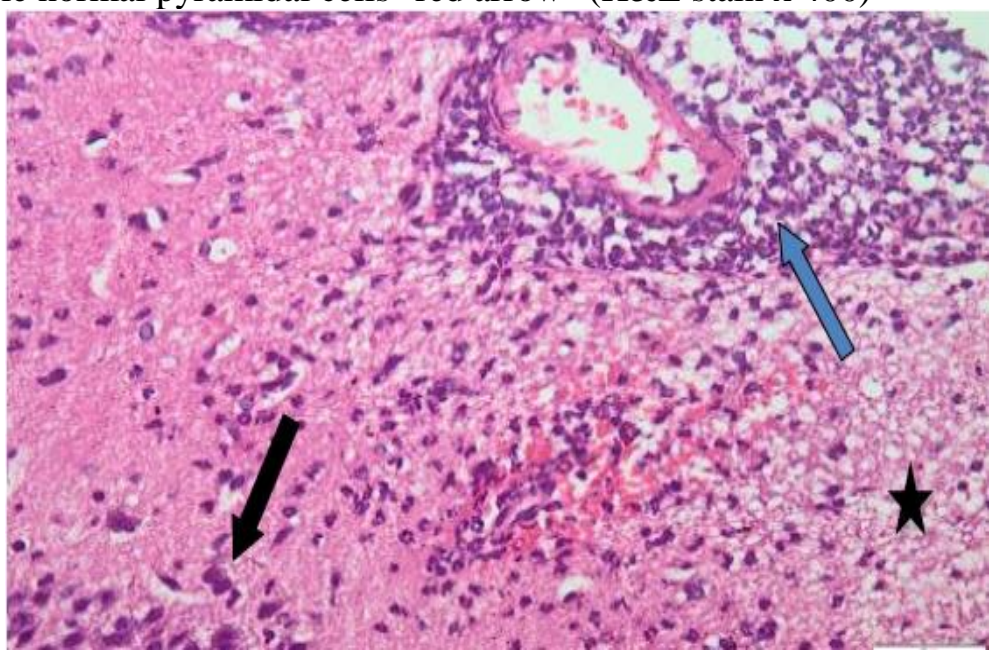

Fig. (9): Brain section of group II showing multiple deformed neurons with dark shrunken nuclei "black arrow" with perivascular cuffing by lymphocytes "blue arrows" and gliosis "black star" (H\& E stain $\mathrm{x} 400)$.

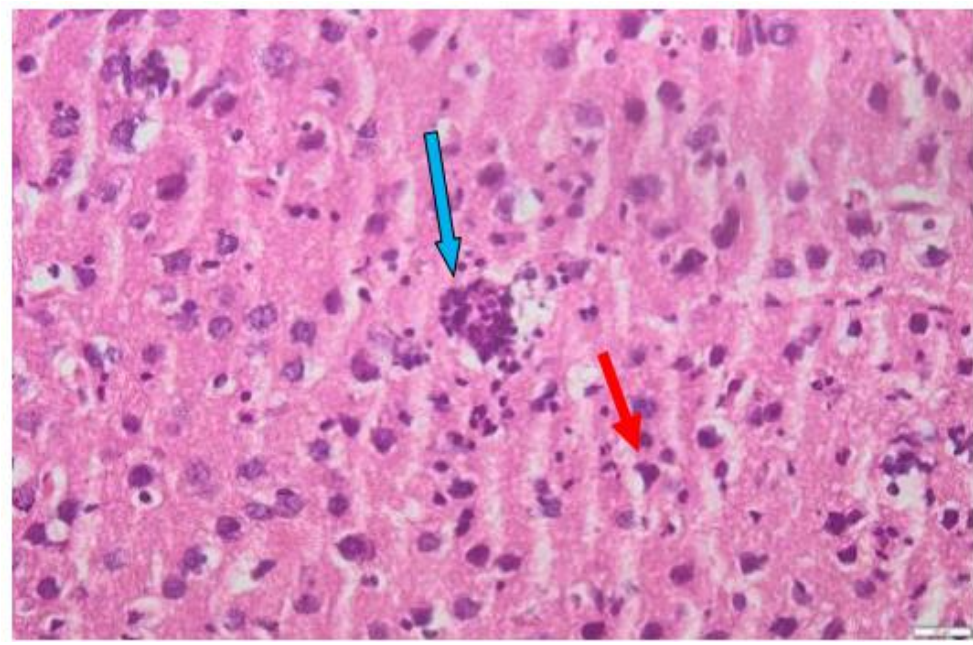

Fig. (10): Brain section of group III showing focal mononuclear inflammatory infiltrate "blue arrow" and scattered normal pyramidal cells "red arrow" (H\&E stain x 400) 


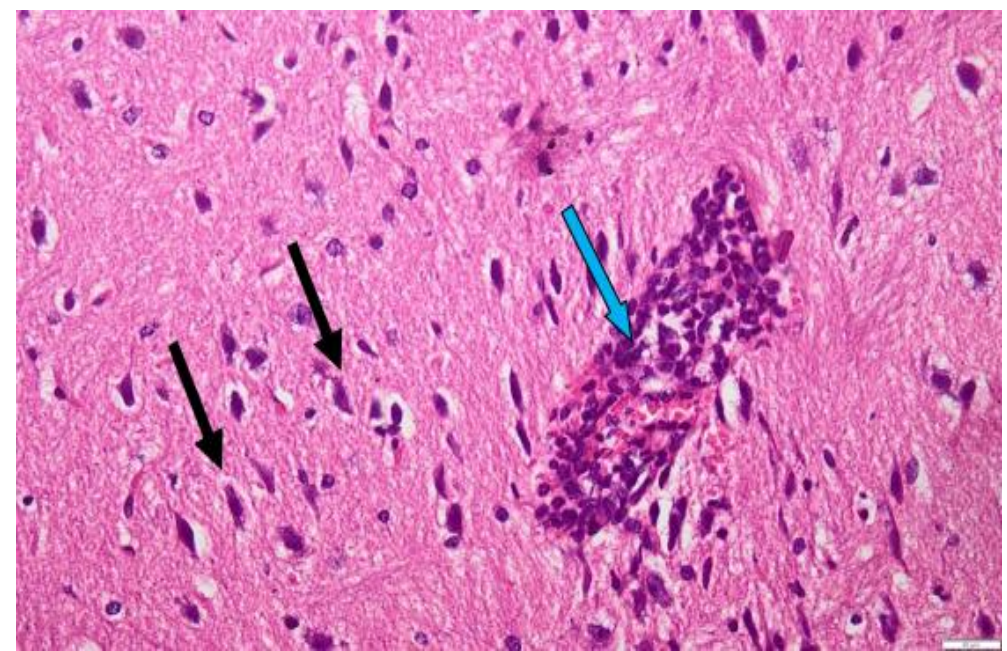

Fig. (11): Brain section of group IV showing cerebral cortex demonstrated few neurons exhibiting acidophilic cytoplasm and dark nuclei, few deformed and shrunken neurons "black arrow" and perivascular cuffing by lymphocytes "blue arrow" (H\&E stain x 400).

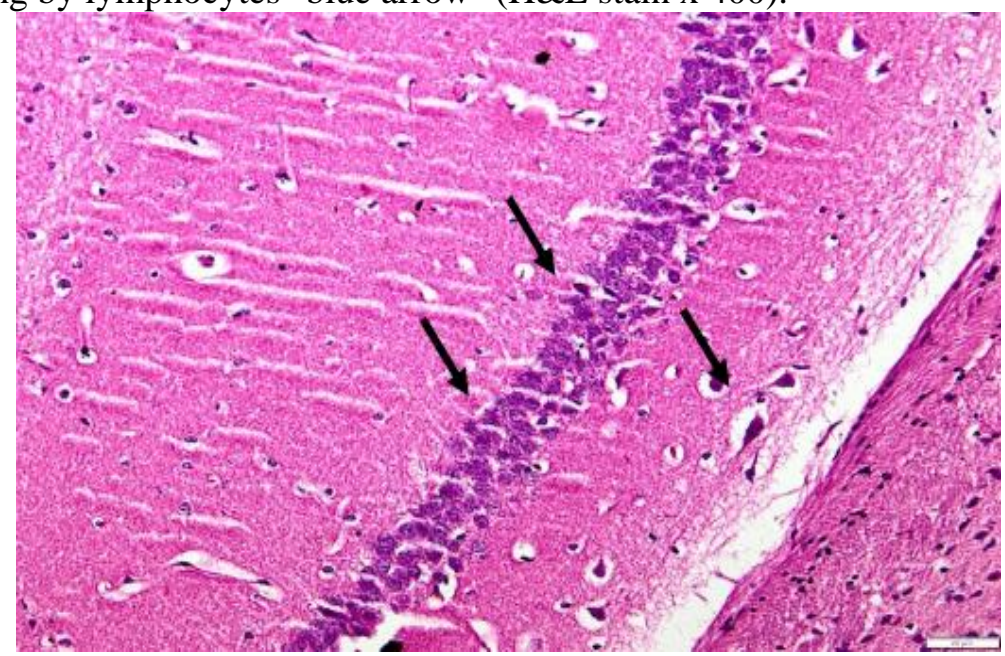

Fig. (12): Brain section of group $\mathrm{V}$ showing normal cerebral architecture with multiple neurons containing large pale vesicular nuclei "black arrow" (H\&E stain x 400)

There was no statistical significance between different groups regarding the size of brain cysts in euthanized mice 7 days and 14 days post treatment (table1).

Table (1): Size of brain cysts in euthanized mice groups 7 days and 14 days post-treatment.

\begin{tabular}{|l|c|c|}
\hline & Euthanized mice $(\mathbf{n}=\mathbf{3})$ after 7 days & Euthanized mice $(\mathbf{n}=\mathbf{3})$ after 14days \\
\hline Group & Mean brain Cyst diameter $\mathbf{\pm}$ SD & Mean brain Cyst diameter $\mathbf{\text { SD }}$ \\
\hline I & $5.16 \pm 0.96$ & $5.16 \pm .25$ \\
\hline II & $4.9 \pm 1.3$ & $5.03 \pm .25$ \\
\hline III & $5.3 \pm 0.76$ & $5.03 \pm .5$ \\
\hline IV & $4.9 \pm 1.2$ & $4.80 \pm 1.04$ \\
\hline
\end{tabular}

One way ANOVA test, after 7 days, $\mathrm{p}$ value $=0.068$

One way ANOVA test, after 14 days, $\mathrm{p}$ value $=0.5$

\section{Mice survival:}

Mice $(n=10)$ from each group were monitored daily and deaths were recorded for 7 months, 2 months post infection. Kaplan-Meier method was used to assess the cumulative survival of mice during the whole experimental period with the results of survival being $100 \%$ and $50 \%$ of group $\mathrm{V}$ and group I respectively (Fig. 14). Group I showed the highest mean survival time 154.3 days, with significant difference from group II (18.2 days) the least survival, group III (93,9 days) and group IV (68.3 days) Fig (13). 


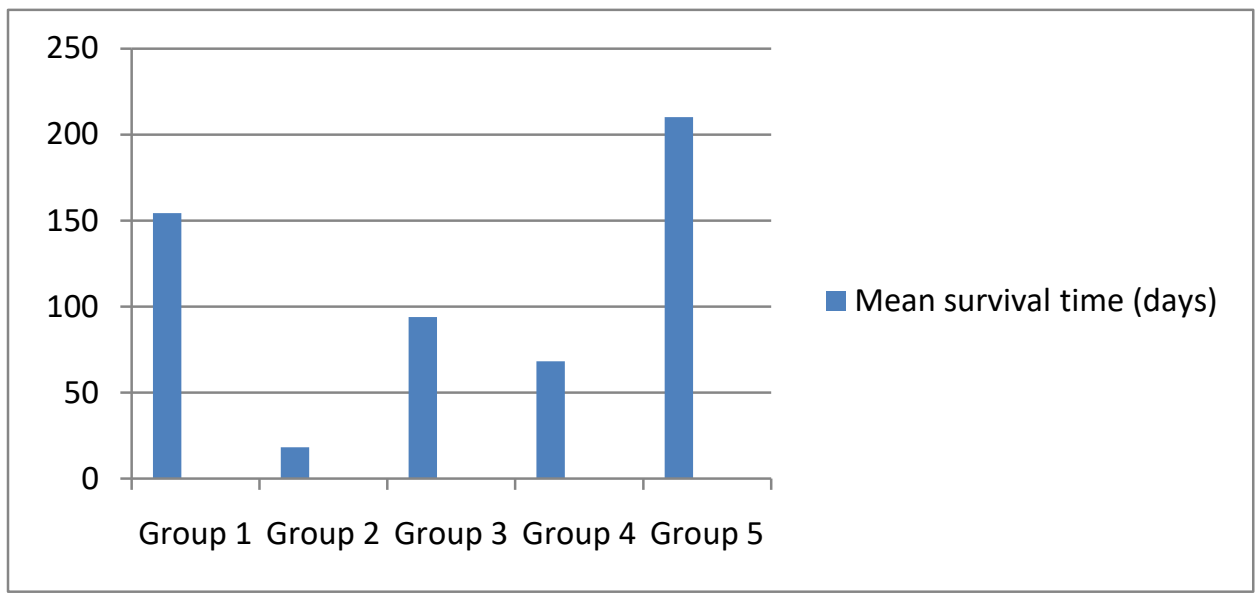

Fig. (13): Mean survival time in all groups for 7 months, 2 months post infection.

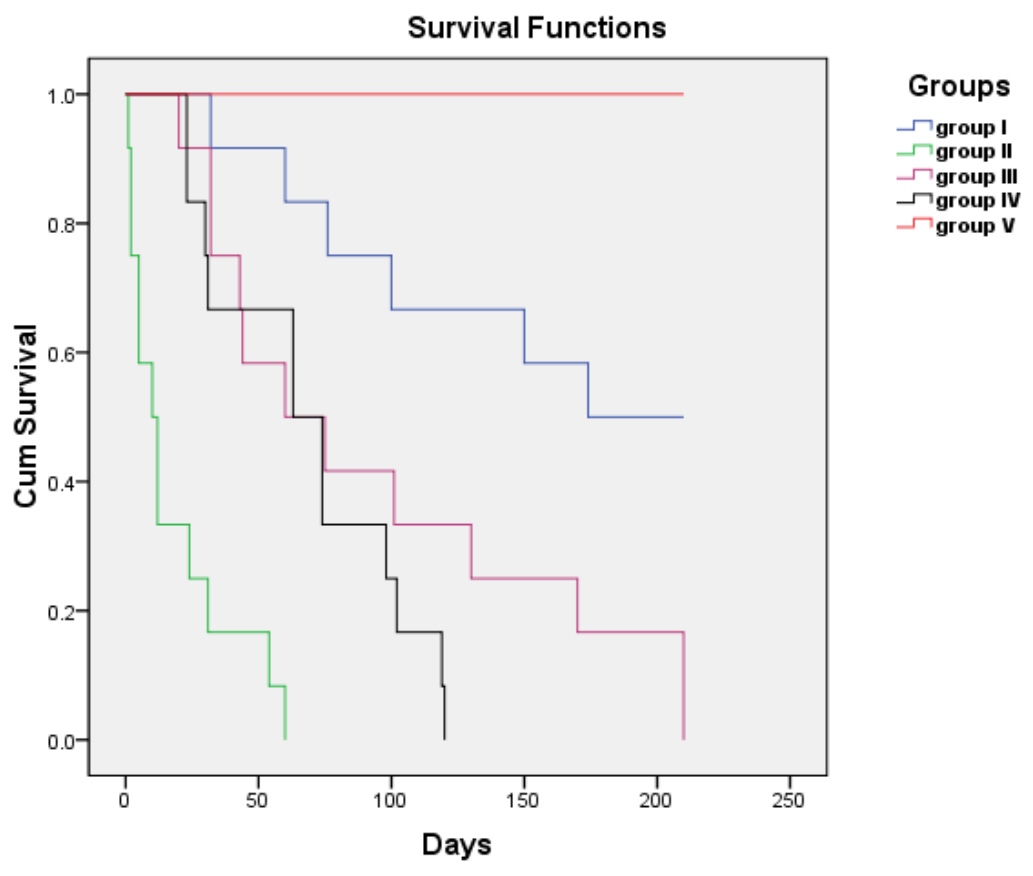

Fig. (14): Kaplan-Meier curve for survival in mice of in all the five groups (10 mice in each group).

\section{DISCUSSION}

T. gondii infection causes important cerebral and behavioural changes in humans. These changes are mainly due to the host immune response against the parasite [26, 27]. The tachyzoites rapidly infect a wide range of host cells. By the effect of the immune system, tachyzoites changed into slowly multiplying bradyzoites. The bradyzoites remains quiescent inside brain cysts for the host's life. Dormant tissue cysts requires a good local immunity in the CNS with the assist of peripheral immune cells that infiltrate the CNS to prevent cyst reactivation and encephalitis [28, 29].
MSCs are used in treatment of brain diseases including tumors, due to their ability in homing in areas with tissue pathology then healing and regeneration occur [30].

This study aimed to assess the potential therapeutic effect of MSCs on chronic murine toxoplasmosis by brain cyst count, histopathological examination and survival analysis.

In the current study, xenogenic transplantation of rat BM-MSCs into infected mice with Toxoplasma was done. This was because rat stem cells could be obtained with more yields of cells

El-Hosseiny et al., Afro-Egypt J Infect Endem Dis 2020;10(2):129-140

https://aeji.journals.ekb.eg/

http://mis.zu.edu.eg/ajied/home.aspx 
in shorter time to avoid contamination of culture dishes. MSCs are hypoimmunogenic and can evade the host immune elimination. It also enhances the cost benefit effectiveness and support the idea of xenogenic MSCs therapy trials in humans. This xenogenic transplantation was previously done with success by different authors who reported successful survival of xenogenic MSCs $[17,31]$.

In this study, mice $(n=5)$ from each group were euthanized by cervical dislocation, on the $7^{\text {th }}, 14^{\text {th }}$ days after starting treatment administration. Such times were proven to be effective for successful testing of the therapeutic MSCs effect on the infected mice [22].

Regarding the mean Toxoplasma cysts count, group I showed non-significant effect ( $p$ value $>0.05$ ) when compared to group IV. MSCs may not have anti-Toxoplasma activity. The cyst structure itself is an effective mean of immune evasion by which the parasite protects itself from immune system and drugs [5]. Group II, showed considerable rise in the mean Toxoplasma cysts count ( $\mathrm{p}$ value $<0.05$ ) compared to group IV and I. This may be due to an imbalance between pro and anti-inflammatory effects of MSCs, when combined with Spiramycin-Metronidazole. Moreover, synergistic immunosuppressive effect may happen, as both MSCs and Spiramycin caused increased level of IL-10 which reduced IFN- $\gamma$ and IL-12 leading to reactivation and fulminant Toxoplasma encephalitis [32, 33]. On the other hand, group III showed important decrease in the mean Toxoplasma cysts count ( $\mathrm{p}$ value $<0.05$ ) compared to group IV and group I. Nevertheless, poor penetration of Spiramycin through the BBB because of the existence of the efflux transporters protein 2 and P-glycoprotein, Metronidazole can prevent the efflux of Spiramycin by inhibiting the efflux transporters present at the BBB, leading to Spiramycinincreased brain uptake [34]. This agreed with authors who used the treatment of SpiramycinMetronidazole, and showed an exceptional effectiveness against chronic cerebral toxoplasmosis. There was a 10 -fold and a 15 -fold decrease in brain cysts compared to the Spiramycin-treated group, and the untreated control group respectively [9]. The antiToxoplasma activity of Spiramycin was also evaluated and showed that in chronic infection, there was a significant decrease in brain cyst burdens [35].
Regarding the histopathological examination in the present study, brain sections of group I showed mild inflammatory changes (score 1) (Fig. 3), while group II, showed marked inflammation, fibrosis (score 3) (Fig. 4). This agreed with authors who reported reduced microglia/macrophages, decreased the peripheral infiltrating leukocytes, reducing proinflammatory cytokines in experimental traumatic brain injury model treated with MSCs [36, 37]. The MSCs are not always immunosuppressive but their effects are determined by the conditions of the microenvironment. Action of certain receptors expressed by MSCs can ascertain their pro or anti-inflammatory effects. Sever inflammation caused by MSCs and Spiramycin-Metronidazole combination, may be due to the previously mentioned synergistic immunosuppressive effect that also caused significant increase in the mean Toxoplasma cysts count [33].

Regarding the survival analysis in the present study, mice in all groups were followed for 7 months after starting treatment administration. $50 \%$ of mice treated with MSCs, survived after 7 months. Group I showed the highest mean survival time (154.3 days) which was significantly higher than the mean survival time of group IV (68.3 days) and group III (93.9 days). This was in accordance with the report about MSCs prolonged survival in Huntington's disease mouse by increasing the laminin, vWf and stromal cell-derived factor-1 [38]. Some authors reported decreased levels of caspase- 3 enzyme in adult rats leading to protection against spinal cord ischemia/reperfusion injury [39].

Group II showed the lowest mean survival time (18.2 days) which is significantly ( $p$ value $<0.05$ ) different from group IV and group III. This high mortality rate in group II goes well with the above results of the increased brain cyst count and severs inflammation in histopathological examination.

In conclusion MSCs exert anti-inflammatory effect on mice chronically infected with $T$. gondii, and prolong their survival, although they can't reduce Toxoplasma- brain cyst count.

Funding: None.

Ethical consideration: The study was approved by the Research Ethics Committee, Faculty of Medicine, Ain Shams University. All the animal experiments were performed according to the 
national regulations for the Animal Ethics rules, Ain-Shams University, Cairo, Egypt.

Conflict of interest: We wish to confirm that there are no known conflicts of interest associated with this publication. We confirm that the manuscript has been read and approved by all named authors and that there are no other persons who satisfied the criteria for authorship but are not listed. We further confirm that the order of authors listed in the manuscript has been approved by all of us.

\section{REFERENCES}

1. CDC Epidemiology of Toxoplasmosis. www.cdc.gov/parasites/toxoplasmosis/epi.html accessed on 3/11/2018.

2. Weiss LM, Dubey JP. Toxoplasmosis: A history of clinical observations. Int J Parasitol 2009; 39(8): 895-901.

3. Dalimi A, Abdoli A. Latent Toxoplasmosis and Human. Iran J Parasitol 2012; 7(1): 1-17.

4. Dogruman-Al F, Fidan I, Celebi B, Yesilyurt E, Erdal B, Babur C, et al. Cytokine profile in murine toxoplasmosis. Asian Pacific Journal of Tropical Medicine 2011; 16-19.

5. Fuentes-Castro BE, Reyes-García JG, Valenzuela-Vargas MT, Martínez-Gómez F. Histopathology of murine toxoplasmosis under treatment with dialyzable leukocyte extract. Mem Inst Oswaldo Cruz, Rio de Janeiro 2017; 112(11): 741-747.

6. Montazeri M, Rezaei K, Ebrahimzadeh MA, Sharif M, Sarvi S, Ahmadpour E. Survey on synergism effect of ketotifen in combination with pyrimethamine in treatment of acute murine toxoplasmosis. Trop Med Health 2017; 21; 45:39.

7. Chew WK, Segarra I, Ambu S, Mak JW. Significant reduction of brain cysts caused by Toxoplasma gondii after treatment with spiramycin coadministered with metronidazole in a mouse model of chronic toxoplasmosis. Antimicrob Agents Chemother 2012; 56(4): 1762-8.

8. Fierro FA, Nolta JA, Adamopoulos IE. Concise Review: Stem Cells in Osteoimmunology. Stem cells 2017; 35(6): 1461-1467.

9. Wang, Y.; Wang, G.; Zhang, D.; Yin, H. and Wang, M. Detection of acute toxoplasmosis in pigs using loop-mediated isothermal amplification and quantitative PCR. Korean $J$ Parasitol. 2013; 51: 573-7.
10. Aleynik A, Gernavage KM, Mourad SH Y, Sherman LS, Liu K, Gubenko YA. Stem cell delivery of therapies for brain disorders. Clin Transl Med. 2014; 3: 24.

11. Bai L, Lennon DP, Caplan AI, DeChant A, Hecker J, Kranso J. Hepatocyte growth factor mediates mesenchymal stem cell-induced recovery in multiple sclerosis models. Nat. Neurosci. 2012; 15: 862-870.

12. Sargent A, Miller RH. MSC Therapeutics in Chronic Inflammation. Curr Stem Cell Rep. 2016; 2(2): 168-173.

13. He Y, Chen D, Yang L, Hou Q, Ma H, Xu X. The therapeutic potential of bone marrow mesenchymal stem cells in premature ovarian failure. Stem Cell Res Ther. 2018; 9: 263.

14. Xu HJ, Qian H, Zhu W, Zhang X, Yan YM, Zhang LL. Mesenchymal stem cells relieve fibrosis of Schistosoma japonicum-induced mouse liver injury. Exp Biol Med. 2012; 237: 585-592.

15. Souza MC, Silva JD, Pádua TA, Torres ND, Antunes MA, Xisto DG. Mesenchymal stromal cell therapy attenuated lung and kidney injury but not brain damage in experimental cerebral malaria. Stem Cell Res Ther. 2015; 6:102.

16. Dameshghi S, Zavaran A, Soudi S, Shirazi FJ, Nojehdehi, S. and Hashemi, SM. Mesenchymal stem cells alter macrophage immune responses to Leishmania major infection in both susceptible and resistance mice. Immunol Lett. 2016; 170:15-26.

17. El-Shennawy SF, Abdel Aaty HE, Radwan NA, Abdel-Hameed DM, Alam-Eldin YH, El-Ashkar AM, et al. Therapeutic Potential of Mesenchymal Stem Cells on Early and Late Experimental Hepatic Schistosomiasis Model. J Parasitol. 2015; 101(5): 587-97.

18. Ahmed, G. Studies on the proliferative potential in culture of mouse embryo fibroblasts of different embryonic ages. Ph.D. Thesis in Histology; University of Essex 2000; Thesis: 324199.

19. Li, H, Fu, X, Ouyang, YS, Cai C, Wang, J and Sun, T. Adult bone-marrow-derived mesenchymal stem cells contribute to wound healing of skin appendages. Cell Tissue Res 2006; 14: 325-335.

20. Sarciron ME, Saccharin C, Petavy AF, Peyron F. Effects of artesunate, dihydroartemisinin, and an artesunate, dihydroartemisinin combination against Toxoplasma gondii. Am. J. Trop. Med. Hyg 2000; 62(1):73-76. 
21. Mahmoud DM, Mahmoud MS, Ezz-El-Din HM, Abo-Zahra FA, Meselhey RA. Artesunate effect on RH virulent and ME49 non-virulent strains of Toxoplasma gondii: in vitro and in vivo experimental studies. Sci Parasitol 2016; 17(34):83-92.

22. Bian P, Ye C, Zheng X, Yang J, Ye W, Wang Y, et al. Mesenchymal stem cells alleviate Japanese encephalitis virus-induced neuroinflammation and mortality. Stem Cell Res Ther. 2017; $8(1): 38$.

23. Abdel aziz MT, Atta HM, Mahfouz S, Fouad HH, Roshdy NK, Ahmed $\mathrm{HH}$, et al. Therapeutic potential of bone marrow derived mesenchymal stem cells on experimental liver fibrosis. Clinical Biochemistry 2007; 40: 893-899

24. Tanaka S, Nishimura M, Ihara F, Yamagishi J, Suzuki Y, Nishikawa Y. Transcriptome analysis of mouse brain infected with Toxoplasma gondii. Infection and Immunity 2013; 81(10):3609-3619.

25. Mose OM, Kamau DM, Kagira JM, Maina N, Ngotho M, Njuguna A, et al. Development of Neurological Mouse Model for Toxoplasmosis Using Toxoplasma gondii Isolated from Chicken in Kenya. Patholog Res Int. 2017; doi: $10.1155 / 2017 / 4302459$.

26. Hermes G, Ajioka JW, Kelly KA, Mui E, Roberts F, Kasza K, et al. Neurological and behavioral abnormalities, ventricular dilatation, altered cellular functions, inflammation, and neuronal injury in brains of mice due to common, persistent, parasitic infection. $J$ Neuroinflammation 2008; 5:48. doi:10.1186/1742-2094-5-48.

27. Bhadra R, Cobb DA, Weiss LM, Khan IA. Psychiatric disorders in toxoplasma seropositive patients - the CD8 connection. Schizophr Bull. 2013; 39:485-489. doi:10.1093/schbul/sbt006.

28. Suzuki Y, Conley FK, Remington JS. Importance of endogenous IFN-gamma for prevention of toxoplasmic encephalitis in mice. $J$ Immunol. 1989; 143:2045-2050.

29. Gazzinelli R, Xu Y, Hieny S, Cheever A, Sher A. Simultaneous depletion of CD4+ and CD8+ T lymphocytes is required to reactivate chronic infection with Toxoplasma gondii. J Immunol 1992; 149:175-180.
30. Trounson A. New perspectives in human stem cell therapeutic research. BMC Medicine 2009; 7(29).

31. Le Blanc $\mathrm{K}$, Tammik $\mathrm{C}$, Rosendahl $\mathrm{K}$, Zetterberg E. and Ringden, O. HLA expression and immunologic properties of differentiated and undifferentiated mesenchymal stem cells. Exp Hematol. 2003 (31): 890-896.

32. Franco PS, Gomes AO, Barbosa BF, Angeloni MB, Silva NM, Teixeira CA, et al. Azithromycin and spiramycin induce anti-inflammatory response in human trophoblastic (BeWo) cells infected by Toxoplasma gondii but are able to control infection. Placenta. 2011; 32(11): 83844.

33. Kyurkchiev D, Bochev I, Ivanova E, Mourdjeva M, Oreshkova T, Belemezova K, Kyurkchiev S. Secretion of immunoregulatory cytokines by mesenchymal stem cells. World J Stem Cells. 2014; 6(5): 552-570.

34. Tan SY, Kan E, Lim WY, Chay G, Law JH, Soo GW...et al. Metronidazole leads to enhanced uptake of imatinib in brain, liver and kidney without affecting its plasma pharmacokinetics in mice. J. Pharm. Pharmacol 2011; 63:918 -925.

35. Gruji'c J, Djurkovi'c-Djakovi'c O, Nikoli'c A, Klun I, Bobi'c B. Effectiveness of spiramycin in murine models of acute and chronic toxoplasmosis. Int J Antimicrob Agents 2005; (25):226-230.

36. Zhang R, Liu Y, Yan K, Chen L, Chen XR, Li P, et al. Anti-inflammatory and immunomodulatory mechanisms of mesenchymal stem cell transplantation in experimental traumatic brain injury. J Neuroinflammation. 2013; 23(10): 106.

37. Hsuan $\mathrm{YC}$, Lin $\mathrm{CH}$, Chang $\mathrm{CP}$, Lin MT. Mesenchymal stem cell-based treatments for stroke, neural trauma, and heat stroke. Brain Behav. 2016; 6(10).

38. Lin YT, Chern Y, Shen CK, Wen HL, Chang YC, Li H, Cheng TH, et al. Human mesenchymal stem cells prolong survival and ameliorate motor deficit through trophic support in Huntington's disease mouse models. PLoS One 2011; 6(8). doi: 10.1371.

39. Yin F, Guo L, Meng CY, Liu YJ, Lu RF, Li P, et al. Transplantation of mesenchymal stem cells exerts anti-apoptotic effects in adult rats after spinal cord ischemia-reperfusion injury. Brain Res. 2014; 2(1561): 1-10. 